\title{
Recerca geològica i mineralògica per les comarques dels Ports i del Matarranya: des del Port de Torre Miró a Mont-roig/Monroyo i a Valjunquera
}

Josep Maria Mata-Perelló

Joaquim Sanz Balagué

Jaume Vilaltella Farràs

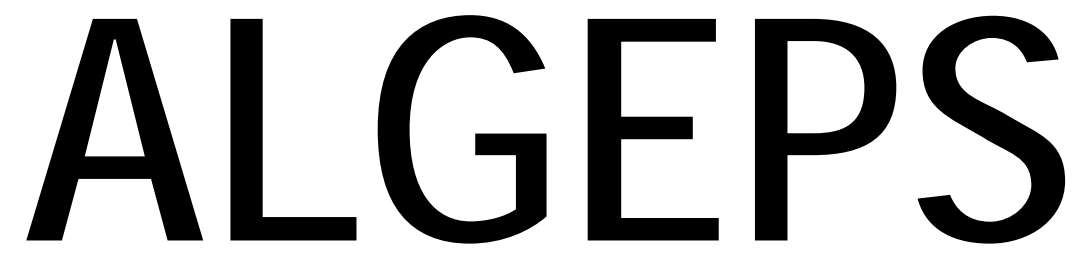

\section{REVISTA DE GEOLOGIA}

\section{n. 3}

JULIOL 2014 


\title{
RECERCA GEOLÒGICA I MINERALÒGICA PER LES COMARQUES DE L'ALT PALÀNCIA, DEL CAMP DE MORVEDRE I PER LA PLANA BAIXA: DES DE SOT DE FERRER I ALGIMIA DE LA BARONÍA A ALGAR DE PALÀNCIA, AZUÉBAR, XÓVAR I A ESLIDA
}

\author{
Josep Maria Mata-Perelló \\ Museu de geologia Valentí Masachs, Escola Politècnica Superior d'Enginyeria de Manresa \\ (EPSEM), Universitat Politècnica de Catalunya · BarcelonaTech (UPC), 08272 Manresa, Spain

\section{Joaquim Sanz Balagué} \\ Departament d'Enginyeria Minera i Recursos Naturals (EMRN), Escola Politècnica Superior \\ d'Enginyeria de Manresa (EPSEM), Universitat Politècnica de Catalunya - BarcelonaTech \\ (UPC), 08272 Manresa, Spain
}

\section{Jaume Vilaltella Farràs}

Paraules clau: Patrimoni geològic i miner; Sistema ibèric; País Valencià

\section{Resum}

Itinerari realitzat el dia 16 de març del 2014. També en aquesta ocasió, el recorregut del present itinerari discorrerà per una zona en la qual conflueixen tres unitats geològiques netament diferenciades: la Depressió Geològica de I'Ebre, la Serralada Prelitoral Catalana (del Sistema Mediterrani), i la Serralada Ibèrica.

Així, en el primer tram del recorregut, entre el Port de Torre Miró i les immediacions de la Pobla d'Alcolea, el recorregut transitarà per la Serralada Ibèrica., encara que dintre de la denominada Zona d'Enllaç de la Serralada Ibèrica amb la Serralada Prelitoral Catalana. La resta del recorregut, es farà per la Depressió Geològica de I'Ebre, encara que dintre de la denominada Zona de I'Avant País Plegat, en els primers trams d'aquest recorregut, pels voltants de Montroig / Montroyo. Tot i així, entre la Sorollera i Rafels, tallarem de nou el Sistema Ibèric, concretament la làmina d'encavalcament de Foz- Calanda - Serra de la Ginebrosa.

Per d'altra banda, el recorregut de l'itinerari, es realitzarà per dues comarques: s'iniciarà a la dels Ports (de la Regió de Castelló), per a finalitzar a del Matarranya (de la Regió de Tortosa).

\section{Objectius fonamentals}

Els objectius fonamentals que es pretenen aconseguir en aquest itinerari, es poden concretar en els següents aspectes generals: 
1. Observació i descripció dels materials mesozoics (en aquest recorregut, del Juràssic i del Cretàcic), que constitueixen la Serralada Ibèrica, a la seva Zona d'Enllaç (amb la Serralada Prelitoral Catalana). Aquests materials els trobarem exclusivament a l'inici del recorregut de l'itinerari, pels voltants del Port de Torre Miró i de la Pobla d'Alcolea. Prop de la Cerollera - Rafels, tornarem a trobar aquest sistema, en creuar la làmina d'encavalcament de Foz-Calanda - Serra de la Ginebrosa.

2. Observació i descripció dels materials terciaris (de I'Eocè i de l'Oligocè) de la Depressió Geològica de l'Ebre, que pertanyen majoritàriament al Grup Guadalope - Castellote. Aquests materials, els anirem trobant a diferents indrets del recorregut, entre la Pobla d'Alcolea i Valljunquera. Tot i això, als primers trams, es circularà dintre del denominat Avant-país, situat al contacte entre la Depressió Geològica de l'Ebre i la Serralada Ibèrica.

3. Observació de les estructures locals d'aquests materials, al llarg del recorregut de l'itinerari, i de les relacions existents entre les tres unitats geològiques acabades d'esmentar, i en especial: visió de les estructures de la Zona d'Enllaç.

4. Observació i reconeixement de diferents mineralitzacions situades a diferents indrets del recorregut de l'itinerari.

5. Observació de les antigues explotacions mineres relacionades amb les mineralitzacions anteriors. Al respecte, cal dir que totes elles es troben actualment aturades.

6. Observació i anàlisi dels impactes produïts sobre el Medi Natural (i sobre el Medi Ambient), tant per les explotacions mineres anteriors, com per altres activitats humanes.

7. Observació dels diferents indrets relacionats amb el Patrimoni Geològic i Miner, que trobarem al llarg del recorregut.

\section{Antecedents}

Pel que fa al recorregut del present itinerari, no coneixem l'existència de gaires antecedents, excepte dels següents: Mata-Perelló (1996a, 1996b, 2001, 2002 i 2014); i també de MataPerelló I Montané García (2003).

Pel que fa a la descripció de les mineralitzacions, cal fer esment d'altres treballs del mateix autor: Mata-Perelló (1991), relatiu al conjunt de les mineralitzacions catalanes en general; i Mata-Perelló (1992), relatius a l'inventari mineralògic de la comarca del Matarranya.

I, finalment, pel que fa a l'estructura geològica de la zona per la qual discorre l'itinerari, farem esment dels treballs de: Guimerà et altri (1982) i de Riba et altri (1976). També, i dintre d'aquest apartat, també farem esment de diversos treballs de I'IGME (1972 i 1976). Tots ells són relatius a diversos fulls geològics corresponents als indrets per on passarà el recorregut de l'itinerari.

Tots aquests treballs referenciats, i d'altres, figuren esmentats per ordre alfabètic a l'apartat dedicat a la Bibliografia.

\section{Recorregut de l'itinerari}

El recorregut de l'itinerari començarà dintre de la comarca dels Ports, concretament al Port de Torre Miró, sobre la carretera N - 232. En aquest indret es farà la primera aturada. Tot seguit es baixarà cap a la població de la Pobla d'Alcolea, per on es farà una nova aturada. 
Posteriorment, després de deixar la comarca dels Ports i d'entrar a la del Matarranya, el recorregut es dirigirà cap el poble de Mont-roig / Monroyo, per on es faran dues noves aturades.

Després, el recorregut continuarà cap el Nord, continuant per la carretera N . 232. Tot i així, per les immediacions de les poblacions de la Sorollera i de Rafels del Matarranya, es faran dues aturades més.

I, finalment, el recorregut després de continuar cap el Nord, arribarà al trencall de Valljunquera, cap on ens caldrà anar, per tal de fer la darrera aturada. Així, el recorregut finalitzarà molt prop d'aquest poble.

\section{Advertiments previs}

Com en altres recorreguts de recerca geològica i mineralògica ..., si es disposa del temps suficient, poden efectuar-se passant per totes les parades i filloles. En cas contrari, recomanem prescindir de les anomenades parades - condicionals.

També recomanem de cercar la informació més adient, sobre els trams a recórrer mitjançant camins de terra, o de pista. Precisament, en aquest itinerari, hi ha alguns trajectes d'aproximació cap a les mines, que haurem de fer per camins de terra en irregular estat de conservació.

Per d'altra banda, recomanem tenir una cura extrema de la natura, evitant qualsevol forma d'agressió sobre ella, o de fer-n'hi un mal ús del que en ofereix la nostra mare Terra.

\section{Descripció de l'ítinerari}

Com de costum, estructurarem el recorregut de l'itinerari en una sèrie de PARADES, que tot seguit anirem veient. En cadascuna d'aquestes aturades farem un breu comentari (geològic 0 mineralògic, segons s'escaigui).

Cada una d'aquestes parades tindrà un número, i un topònim representatiu. Per d'altra banda, s'indicarà el nom del poble més proper, el municipi al qual pertany l'indret, i la comarca on es troba situat. Per d'altra banda, també indicarem en cada cas, i entre parèntesi, el full topogràfic on es troba l'aturada.

Finalment, cal dir que el recorregut de l'itinerari s'inclourà dintre dels següents fulls, del "Mapa Topográfico Nacional", realitzats a l'escala 1:50.000 per I'"Instituto Geográfico y Catastral": 495 (o de Castelserás) i $\mathbf{5 2 0}$ (dit de Pena-roja de Tastavins).

Així doncs, la relació de parades ordenades, que composen aquest itinerari geològic i mineralògic, és el següent:

\subsection{PARADA 1. COLL DE TORRE MIRÓ, PLECS DEL TALÚS DE LA CARRETERA N - 232, (terme municipal de Morella, Comarca dels Ports). (Full 520)}

El recorregut d'aquest itinerari el començarem en aquest indret. Es troba situat sobre la carretera nacional $\mathrm{N}-232$, a l'actual Port de Torre Miró, per les immediacions del Km 71 de l'esmentada carretera, dintre del terme de Morella a la comarca castellonenca dels Ports. 
Aquest indret es troba situat entre els afloraments dels materials mesozoics que formen part de la Zona d'Enllaç de la Serralada Prelitoral Catalana amb la Serralada Ibèrica, tot i que ens trobem ja quasi plenament en aquesta darrera.

En aquest indret podem observar un impressionant tren de plecs. Sobre aquest aflorament val a dir que el plegament és molt més intens del que apreciem a primer cop d'ull. Si ens fixem en la meitat de la dreta del talús podrem veure "una capa" competent i de color més clar que no té continuïtat en l'altre flanc dels plecs. De fet aquesta "capa" no ens permet de veure l'altre flanc doncs es tracta d'una xarnera d'un plec sinclinal que ha estat aïllada en fer-se la carretera.

D'aquesta observació es desprèn que aquests plecs estan molt més comprimits del què sembla doncs, en tallar una superfície plegada el màxim de deformació l'observem quan la secció és perpendicular a la direcció de la deformació. (fotografia 1)

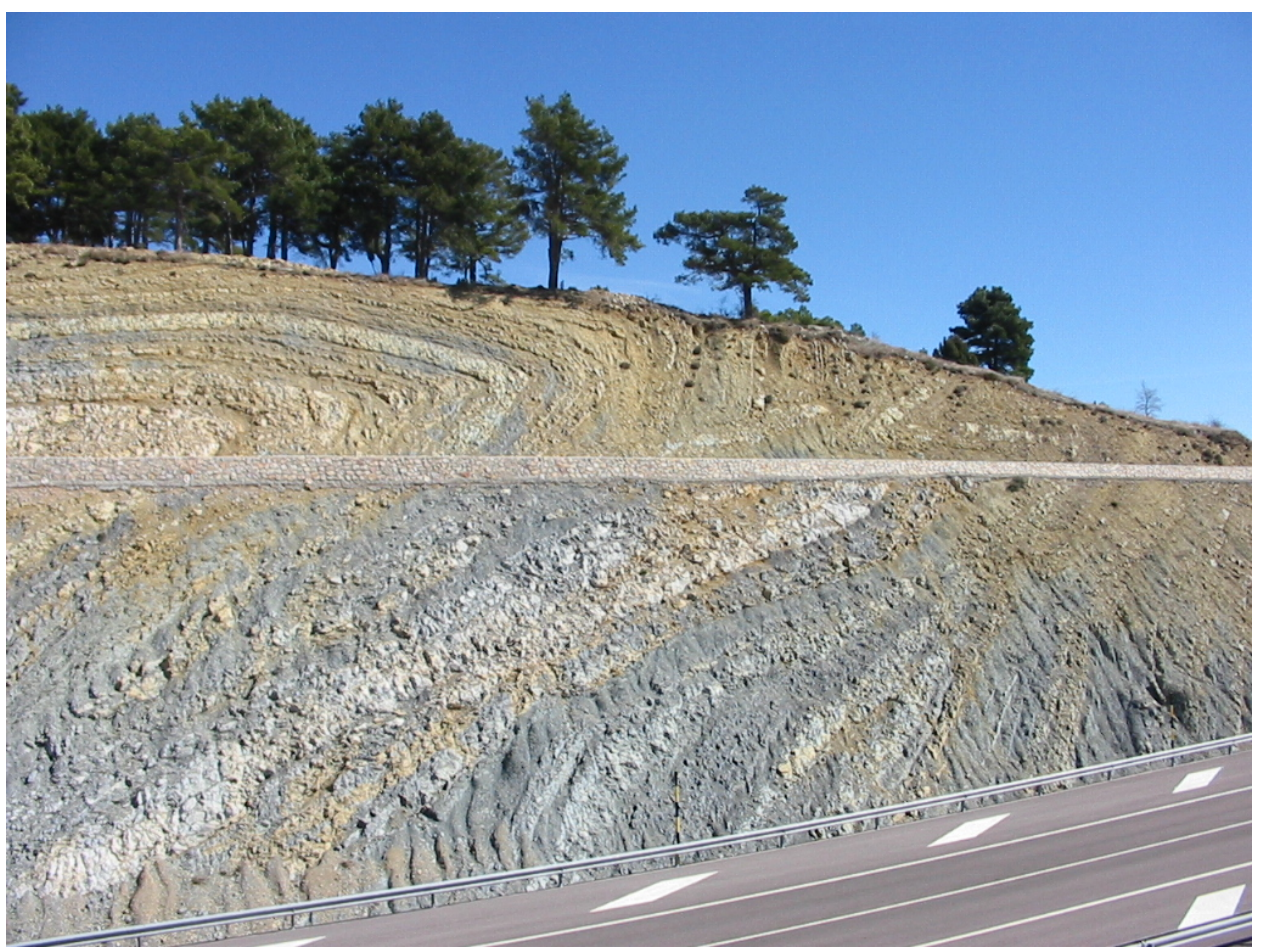

FOTOGRAFIA 1.Plecs del talús de la carretera a Torré Miró

\subsection{PARADA 2. IMMEDIACIONS DE LA POBLA D’ALCOLEA, CARRETERA N - 232, (la Pobla d'Alcolea, terme municipal de Morella, Comarca dels Ports). (Full 520)}

Després de fer l'aturada anterior, cal fer un breu recorregut per la carretera $\mathrm{N}-232$, anant cap el Nord (cap la ciutat d'Alcañíz i cap a Zaragoza). En arribar a les immediacions de la localitat de la Pobla d'Alcolea, farem una nova aturada; així, haurem recorregut uns $4 \mathrm{Km}$, aproximadament, els quals els haurem fet per I variant d'aquesta carretera.

En aquest recorregut, hem anat trobant afloraments dels materials mesozoics que hem vist a l'aturada anterior. Aquests materials, fonamentalment carbonatats, pertanyen al Cretàcic i al 
Juràssic i es troben dintre de la Serralada Ibèrica, a la denominada Zona d’Enllaç amb la Serralada Prelitoral Catalana. Així, predominen els arrumbaments ibèrics, de direcció ONO ESE, fonamentalment. Tot i així, sovint es troben tallats per fractures de direcció "catalana", de direccions generalitzades de components NNE - SSW i NE - SW.

En arribar a aquest indret, situat per sobre de la carretera, al talús meridional, es pot gaudir d'una bona visió dels afloraments d'aquests materials mesozoics, veient al mateix temps, al fons la Depressió Geològica de l'Ebre, situada més al Nord de la Pobla d’Alcolea. Entre mig s'entreveuen els relleus de la làmina d'encavalcament de Foz-Calanda - Serra de la Ginebrosa. (fotografia 2)

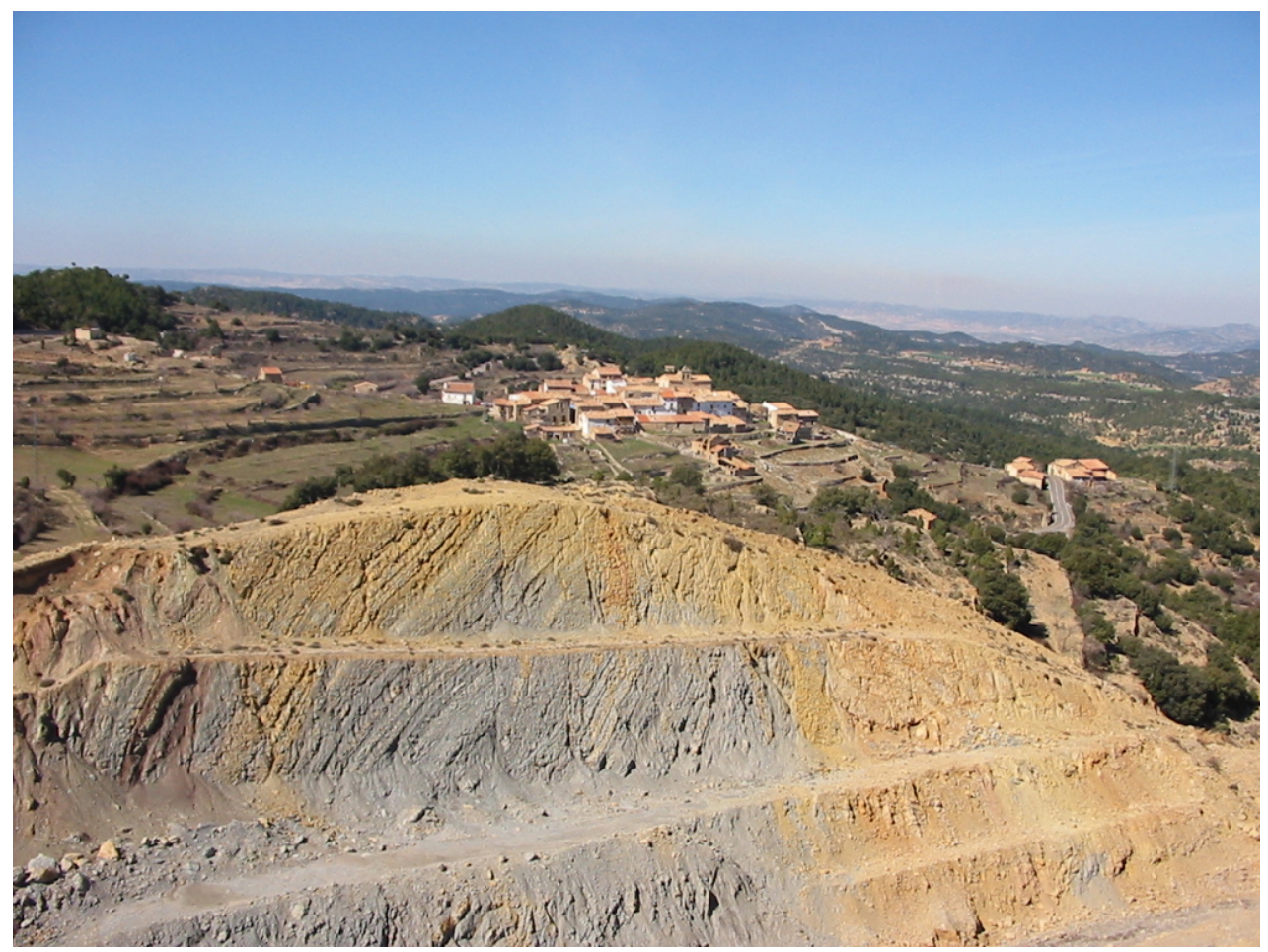

FOTOGRAFIA 2. Afloraments al marge de la carretera $\mathrm{N}-232$ dels materials mesozoics de la Serralada Ibèrica. Cap el fons, més enllà de la Pobla d'Alcolea, ja es veu la Depressió Geològica de l'Ebre

\subsection{PARADA 3 - CONDICIONAL. SORTIDA DE MONT-ROIG CAP A PENA-ROJA DE TASTAVINS, CARRETERA A - 1414, (terme municipal de Mont-roig I Monroyo, comarca del Matarranya). (Full 520).}

Després de realitzar la parada anterior, caldrà continuar per la carretera nacional $\mathrm{N}-232$, anant sempre cap el Nord. Així, aviat s'arribarà a la comarca del Matarranya, deixant enrere la dels Ports. Poc després s'arribarà a la població aragonesa de Mont-roig / Monjoio. En sobrepassar-la, caldrà fer una petita fillola per la carretera autonòmica A - 1414, tot anant cap a Pena-roja de Tastavins / Peñarroya de Tastavins. A uns 0’2 Km del primer poble esmentat i a uns13 Km de l'aturada anteriorment efectuada, en caldrà fer una altra, si s'escau.

En aquest llarg recorregut, hem anat trobant els materials esmentats a les dues anteriors aturades; és a dir: els afloraments dels materials mesozoics que formen part de la Serralada Ibèrica, dintre de la seva zona d’Enllaç amb la Serralada Prelitoral Catalana. Aquests materials 
mesozoics són fonamentalment carbonatats i pertanyen al Cretàcic (ocasionalment també al Juràssic).

Més endavant, en sobrepassar el terme de Torredarques / Torre de las Arcas, de la comarca del Matarranya, deixarem els afloraments mesozoics i començarem a trobar afloraments dels materials cenozoics de la Depressió Geològica de l'Ebre. És a dir: haurem sobrepassat el contacte d'aquesta darrera unitat amb la Serralada Ibèrica, que a molts indrets encavalca I'anterior, tot i que haurà no ho haurem vist

Pel que fa a l'indret de l'aturada, a l'igual que el poble, es troba situat al bell mig de la Depressió Geològica de l'Ebre i més concretament a la denominada Zona de I'Avant-país plegat. Així, per arreu es fan palesos els afloraments dels materials ocres, de característiques detrítiques.

Aquests materials són cenozoics, i pertanyen probablement al complex de Mont-roig, Aiguaviva i Alcorisa. Pertanyen a I'Oligocè i es troben força replegats, i en alguns sectors encavalquen als nivells calcolutítics i sorrencs del Grup del Castellote - Matarranya.

Entre aquests materials es troben abundants paleocanals, excavats entre els gresos i els trams calcolutítics. Aquests paleocanals es troben reblerts per conglomerats, la qual cosa produeix sovint inversions de relleu.

\subsection{PARADA 4. TELLERIA DE L'ERMITA DE LA CONSOLACIÓ, (terme municipal de Mont-roig I Monroyo, comarca del Matarranya). (Full 520).}

Després de fer l'aturada anterior, cal retrocedir cap el poble de Mont-roig / Monroyo, desfent la fillola. Ara, des d'aquí, ens caldrà continuar cap el Nord, seguint la carretera nacional N - 232. Més endavant, en arribar a les immediacions del Km 96, ens caldrà agafar un trencall per I'esquerra, el qual es dirigeix cap a l'Ermita de la Consolació. Prop d'aquesta, en una antiga teuleria (telleria), farem una nova aturada a uns $3^{\prime} 5 \mathrm{Km}$ de l'anterior.

En aquest recorregut. Hem anat trobant afloraments dels materials cenozoics esmentats a I'aturada anterior. Així, com abans, ens trobem situats dintre de la Depressió Geològica de I'Ebre, entre afloraments de materials de tonalitats ocres, de caràcter calcolutitic i gresenc.

En aquest indret hi ha les restes d'una antiga teuleria (forn d'obra o telleria). Aquesta es troba lleugerament conservada. Tot i així, forma part del Patrimoni Miner de la comarca del Matarranya. (fotografia 3)

Finalment, cal dir que en aquesta telleria s'utilitzaven les calcolutites properes cenozoiques, del Grupo de Castellote - Matarranya. 


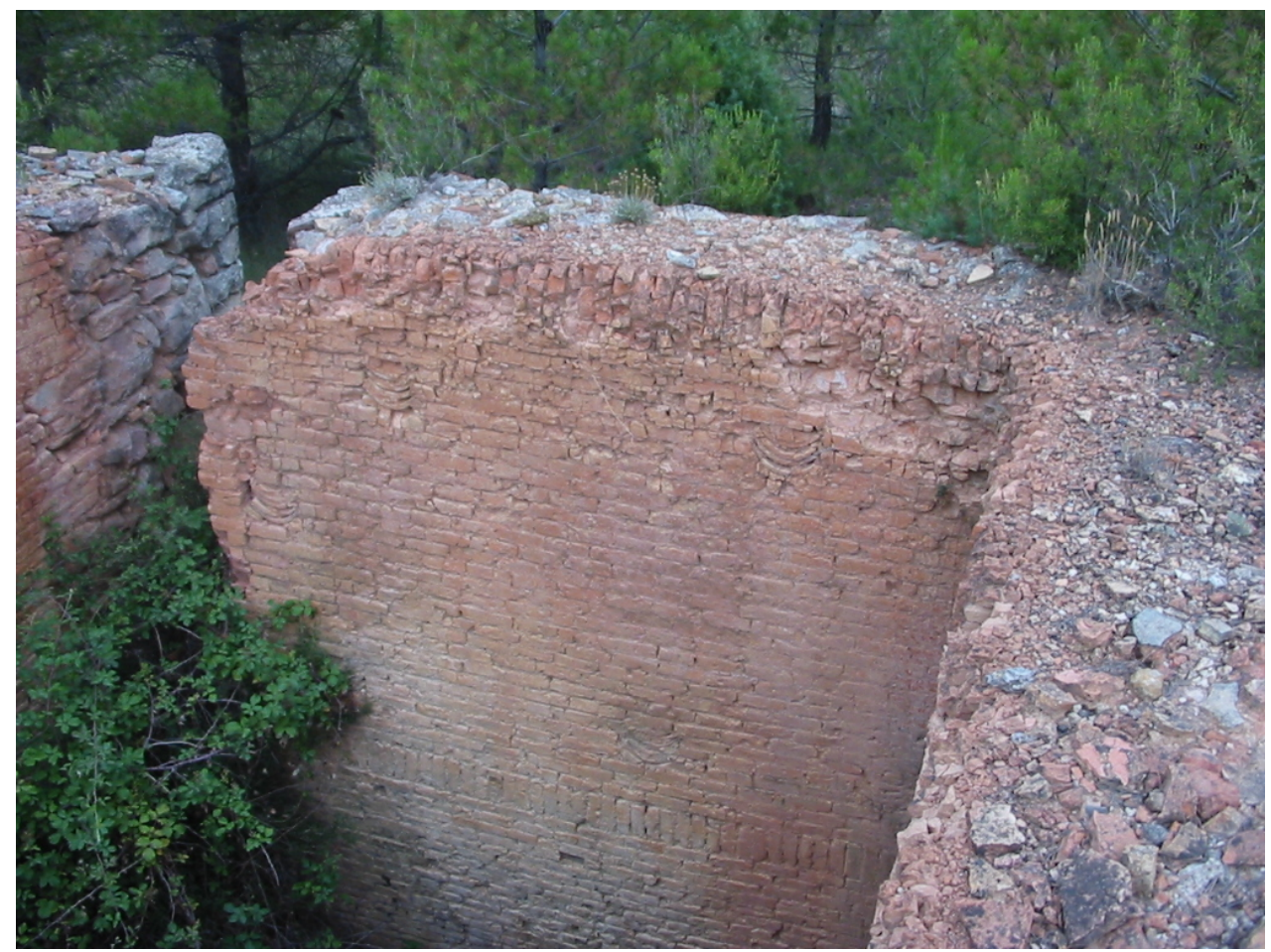

FOTOGRAFIA 3. Restes de la Telleria de l'Ermita de la Consolació. Mont-roig / Monroyo

\subsection{PARADA 5. ANTIGUES EXPLOTACIONS D’ARGILA I DE CARBÓ DE LES IMMEDIACIONS DE LA CORBATERA, (terme municipal de la Sorollera / la Cerollera, antigament de la comarca del Matarranya i ara de la del Bajo Aragón - Alcañíz). (Full 495).}

Després de fer l'aturada anterior, cal continuar cap el Nord, seguint sempre la carretera nacional $\mathrm{N}-232$. A uns $5 \mathrm{Km}$ de la parada anterior, es trobarà per l'esquerra el trencall de la Sorollera / la Cerollera. Poc després, a quasi $1 \mathrm{Km}$, es trobarà un camí per l'esquerra, que ens caldrà agafar, situat prop del Km 102 de la carretera. Aquest condueix a unes antigues explotacions (situades entre 1 i 1'5 $\mathrm{Km}$ de la carretera), per on farem una nova aturada. Així, des de la parada anterior haurem recorregut uns 7’5 Km.

En aquest recorregut, haurem trobat inicialment els materials cenozoics esmentats a les aturades anteriors, situats dintre de la Depressió Geològica de l'Ebre. Tot i així, en arribar a les corbes de la Corbatera, haurem començat a trobar afloraments dels materials mesozoics, de caràcter eminentment carbonat, del Cretàcic. Aquests materials que han estat explotat en diferents pedreres, es situen dintre del Sistema Ibèric, dintre de la Zona d'Enllaç amb la Serralada Prelitoral Catalana. Tot i així, aquí formen part de la làmina d'encavalcament de FozCalanda - Serra de la Ginebrosa. Aquesta encavalca al materials cenozoics anteriorment esmentats.

Pel que fa a l'indret de la present aturada, cal dir que aquest es relaciona amb un aflorament dels materials cretàcics de l'Albià, situats dintre de la làmina d'encavalcament anteriorment esmentada. Així, aquí es fan palesos els nivells de la Formació Escucha i també els de la Formación Utrillas; tot i que predominen els primers. Entre els materials es fan ben ostensibles 
uns nivells de caolinita molt negra i nivells de lignits. Aquests materials han estat explotats en diferents indrets, dintre d'aquesta zona. (fotografia 4)

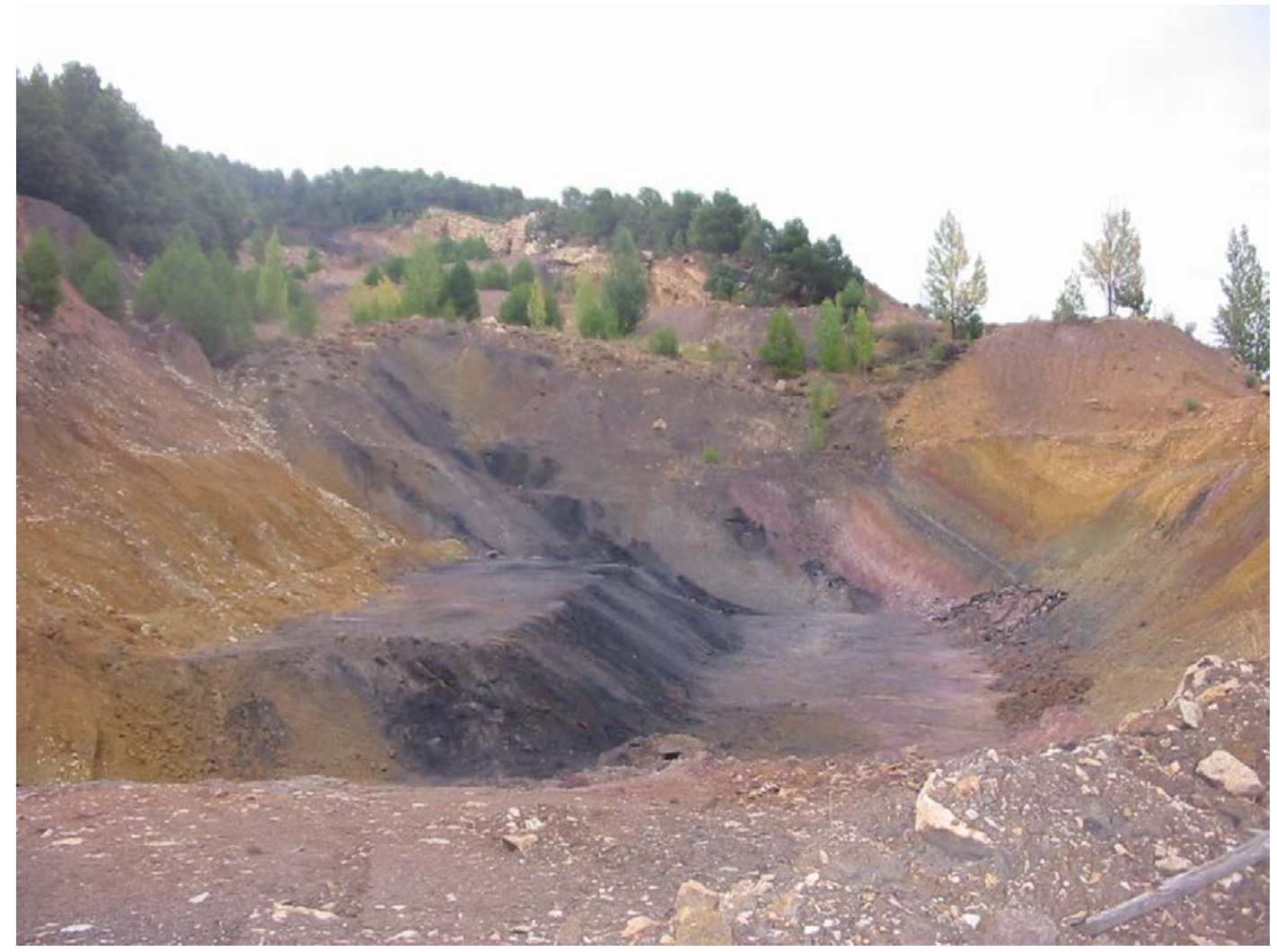

FOTOGRAFIA 4. Afloraments dels caolins i dels lignits de la Formació Escucha. La Sorollera / la Cerollera. 2005

\subsection{PARADA 6 - CONDICIONAL ANTIGUES EXPLOTACIONS D'ARGILA DE RAFELS, (terme municipal de Rafels / Rafales, comarca del Matarranya). (Full 520).}

Després de fer l'aturada anterior, cal retornar cap a la carretera $N-232$, per tal de fer un breu recorregut, fins trobar a $1 \mathrm{~km}$ el trencall que condueix cap al poble de Rafels / Rafales. Ens caldrà agafar aquest vial, per tal d'arribar fins al poble esmentat. En arribar anirem a unes antigues explotacions caolins situades a la Gramanella, a quasi $1 \mathrm{Km}$ al sud del poble. Aquí, si s'escau farem una aturada, a uns $10 \mathrm{Km}$ de l'aturada anteriorment efectuada.

En aquest recorregut, ens hem estat desplaçant per la làmina d'encavalcament de FozCalanda - Serra de la Ginebrosa. Així, fonamentalment, hem anat trobant afloraments dels materials mesozoics del Cretàcic. Ara mateix, en aquest indret, hi ha un aflorament dels materials de I'Albià, concretament els de la Formació Utrillas. Aquests materials han estat explotats en aquest lloc. FOTOGRAFIA 5. 


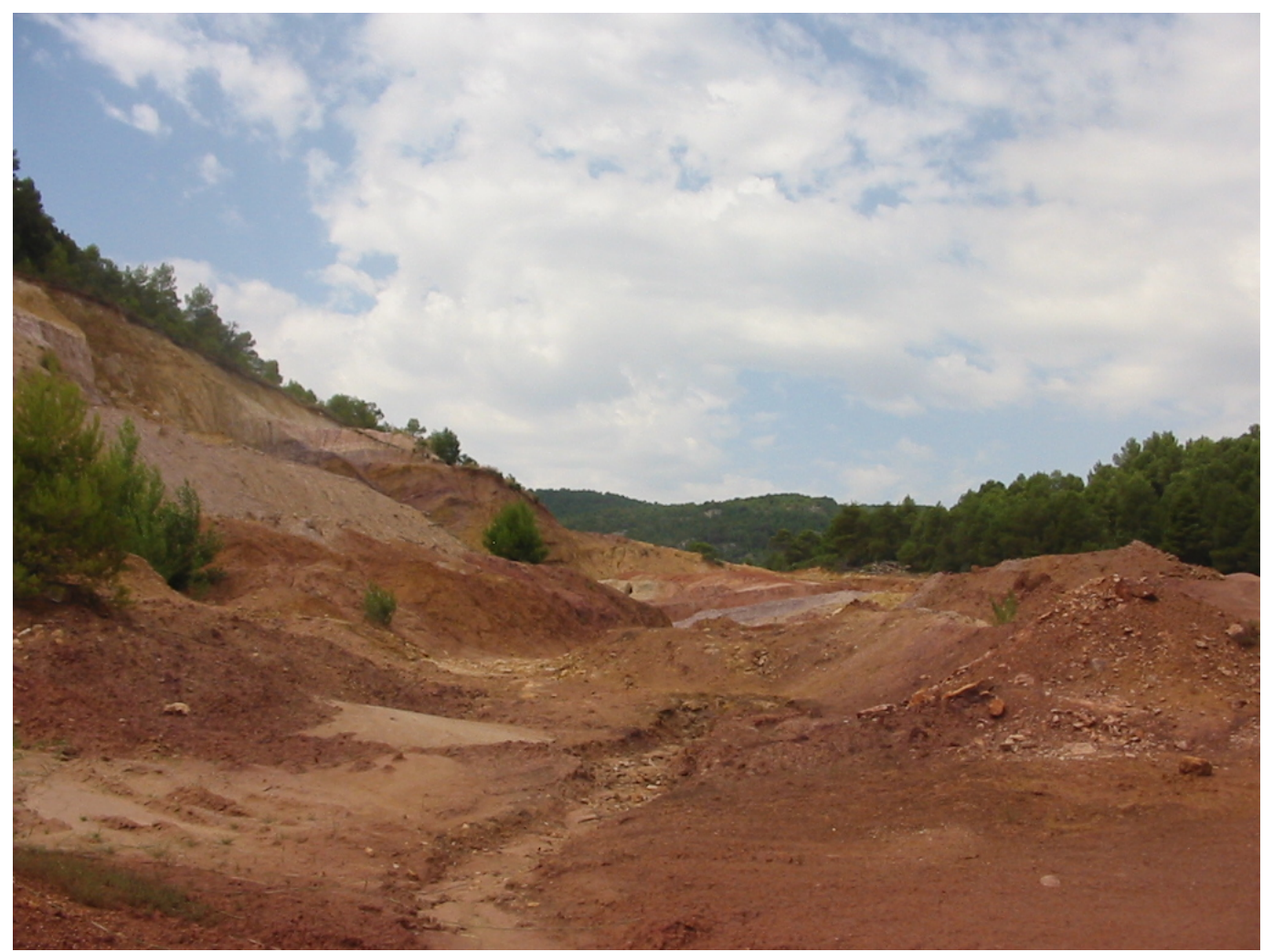

FOTOGRAFIA 5. Aflorament i explotació de materials cretàcics caolinífers de la Formació Utrillas, Rafels/Rafales. 2006

\subsection{PARADA 7. TELLERIA DE VALLJUNQUERA, (terme municipal de Valljunquera I Valjunquera, comarca del Matarranya). (Full 495).}

Després de realitzar l'aturada anterior, cal desfer completament la fillola, retornant de nou cap a la carretera $\mathrm{N}$ - 232. En trobar-la, ens caldrà continuar cap el Nord. Així, més endavant, a uns $15 \mathrm{Km}$, trobarem la carretereta que surt per la dreta i que condueix cap el poble de Valljunquera I Valjunquera. En trobar aquesta carretera (la $A-231$ ), ens caldrà agafar-la i en uns $4 \mathrm{Km}$, trobarem per la dreta el trencall que condueix cap a la Telleria (a la Font de la Telleria), a $1 \mathrm{Km}$ abans d'arribar al poble. Així, des de la parada anterior, haurem efectuat un llarguíssim recorregut, molt proper als $22 \mathrm{Km}$

En aquest recorregut, inicialment hem trobat els materials mesozoics esmentats a l'aturada anterior, els materials del Cretàcic, que ara són fonamentalment carbonatats, de la làmina d'encavalcament de Foz-Calanda - Serra de la Ginebrosa. Tot i així, més endavant, prop del primer $\mathrm{Km}$ després d'haver retornat a la carretera $\mathrm{N}-232$, trobarem de nou els materials cenozoics de la Depressió Geològica de l'Ebre. Així, haurem passat de nou del Sistema lbèric a la depressió que hem acabat d'esmentar. Aquest contacte es realitza per un encavalcament de la serralada sobre la depressió.

A partir d'aquest indret, hem anat trobant afloraments dels materials cenozoics, de caràcter calcolític i gresenc, segons els indrets, amb freqüents paleocanals. Aquests materials que reblen la Depressió Geològica de I'Ebre, es situen dintre del al Grup Guadalope - Castellote. Aquest són també els materials que apareixen a l'indret de la present aturada. 
En aquest indret hi ha un interessant conjunt patrimonial, entre el qual destaquen les restes d'una antiga teuleria (Font d'Obra o Telleria), i també les restes de una font, anomenada "Font de la Telleria". En aquesta "telleria" s'aprofitaven uns materials calcolutitics explotats prop de I'indret. Tanmateix s'utilitzava l'aigua del barranc proper, de les immediacions de la font.

Pel que fa a la telleria, tot i el seu estat, formen part del Patrimoni Miner de la comarca del Matarranya. (fotografies 6 i 7 )

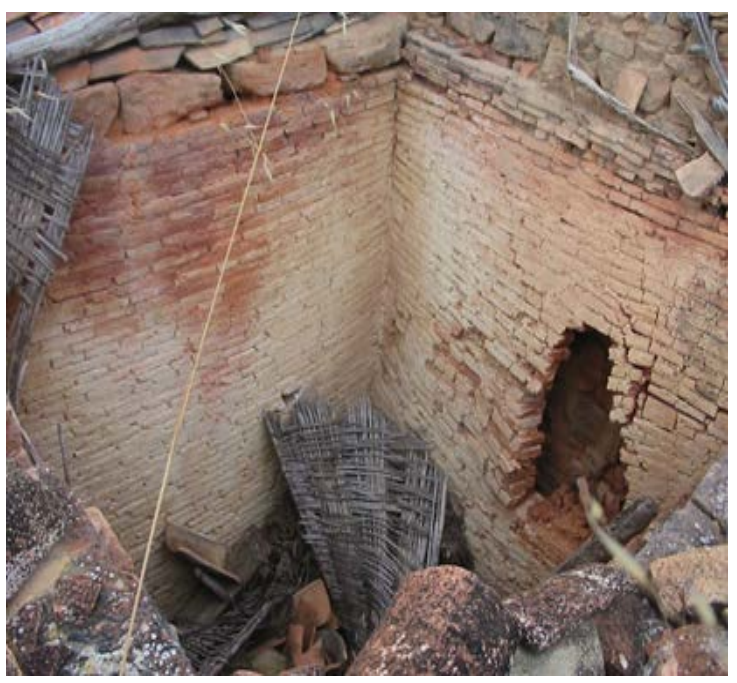

FOTOGRAFIA 6. Restes de la Telleria de Valljunquera

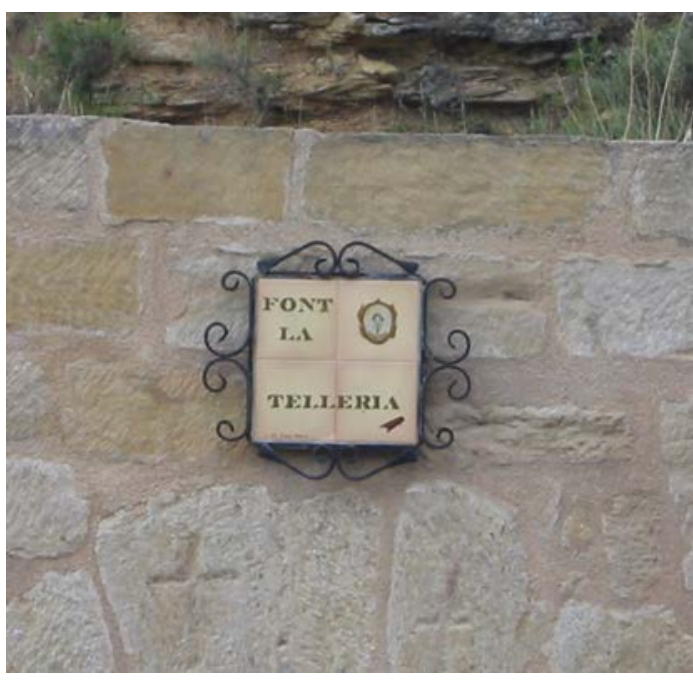

FOTOGRAFIA 7. Font de la Telleria de Valljunquera

En aquest indret finalitza el recorregut de l'itinerari.

\section{Referències bibliogràfiques}

GUIMERÀ, J. et altri (1992).- Geologia (II), Història Natural dels Països Catalans, Vol.2, 547 pag. Enciclopèdia Catalana, S.A. Barcelona.

IGME (1972).- Mapa Geológico de España a escala 1:200.000. Sintesis de la Cartografia existente. Hoja y memória no. 41 (Tortosa). Inst. Geol. Min. España. Minist. Indústria. Madrid.

IGME (1974).- Mapa Metalogenético de España a escala 1:200.000. Hoja y memória $n^{\circ} .41$ (Tortosa). Inst. Geol. Min. España. Minist. Indústria. Madrid.

IGME (1975).- Mapa de Rocas Industriales de España a escala 1:200.000. Hoja y memória $\mathrm{n}^{\circ}$. 41 (Tortosa). Inst. Geol. Min. España. Minist. Indústria. Madrid.

IGME (1976).- Mapa Geológico de España a escala 1:50.000. Segunda Sèrie. Hoja y memó. $\mathrm{n}^{\circ}$ 520 (Pena-roja de Tastavins). Inst. Geol. Min. España. Min. Indús. Madrid.

IGME (1977).- Mapa Geológico de España a escala 1:50.000. Segunda Sèrie. Hoja y memó. no 545 (Morella). Inst. Geol. Min. España. Min. Indús. Madrid. 
MATA-PERELLÓ, J.M. (1992).- Inventario Mineralógico de la Tierra Baja - Matarraña, Revista Rodeno, $n^{\circ} 30,28$ pag. Manresa.

MATA-PERELLÓ, J.M. (1994).- Inventàri Mineralògic de la comarca del Matarranya, Terra Endins, $\mathrm{n}^{\circ} 6,23$ pag. Manresa.

MATA-PERELLÓ, J.M. (1996a).- Itinerari geològico - mineralògic per les comarques del Matarranya i de la Tierra Baja-Guadalope: des de Calaceit a Vall-de-roures, Fondespatla, la Canyada de Beric i Alcanyís. Inèdit. 14 pàgines. Manresa

MATA-PERELLÓ, J.M. (1996b).- Itinerari geològico - mineralògic per les comarques del Matarranya i de la Tierra Baja-Guadalope: des de Calaceite / Calaceit a Valderrobres / Vall-deroures i Alcañíz / Alcanyís. Inèdit. 14 pàgines. Manresa

MATA-PERELLÓ, J.M. (2001).- Recorregut de recerca geològica i mineralògica per les comarques del Matarranya i dels Ports: des de Mont-roig i Pena-roja de Tastavins a Herbers i a Morella. Inèdit. 11 pàgines. Manresa

MATA-PERELLÓ, J.M. (2002).- Recorregut de recerca geològica i mineralògica per les comarques del Baix Maestrat i dels Ports: des de Vinaròs a Morella i a Montroig, i des de Penaroja de Tastavins a les Tallades. Inèdit. 15 pàgines. Manresa

MATA-PERELLÓ, J.M. i MONTANÉ GARCIA , P. (2003).- Ruta de reconeixement geològic i mineralògic de la zona dels Ports de Beseit: des de Vall-de-roures a Fredes. Inèdit. 12 pag. Manresa

RIBA, O. et altri (1976).- Geografia Física dels Països Catalans, Edit. Ketres, 254 pàgines. Barcelona. 